\title{
Vacuolar Acidification in Citrus Fruit: Comparison between Acid Lime (Citrus aurantifolia) and Sweet Lime (Citrus limmetioides) Juice Cells
}

\author{
Andreas Brune ${ }^{1}$ \\ Citrus Research and Education Center, Institute of Food and Agricultural Sciences, University of \\ Florida, 700 Experiment Station Road, Lake Alfred, FL 33850 \\ Mathias Müller ${ }^{2}$ and Lincoln Taiz ${ }^{3}$ \\ Department of Biology, University of California, Sinsheimer Laboratories, Santa Cruz, CA 95064 \\ Pedro Gonzalez ${ }^{4}$ and Ed Etxeberria ${ }^{5}$ \\ Citrus Research and Education Center, Institute of Food and Agricultural Sciences, University of \\ Florida, 700 Experiment Station Road, Lake Alfred, FL 33850
}

\begin{abstract}
AdDitional INDEX words. V-ATPase, citrus, vacuolar $\mathrm{pH}$, vacuole, V-PPase
Abstract. Vacuolar acidification was investigated in 'Palestine' sweet (Citrus limmetioides Tanaka) and 'Persian' acid lime [(Citrus aurantifolia (Christm.) Swingle] (vacuolar pHs of 5.0 and 2.1, respectively) using tonoplast vesicles isolated from juice cells. The ATPase activity of tonoplast-enriched vesicles from sweet limes was strongly inhibited by bafilomycin $\mathrm{A}_{1}$ and $\mathrm{NO}_{3}{ }^{-}$, but was unaffected by vanadate. In contrast, the ATPase activity in acid lime membranes was only slightly inhibited by bafilomycin $\mathrm{A}_{1}$ and $\mathrm{NO}_{3}{ }^{-}$and was strongly inhibited by high concentrations of vanadate. The vacuolar origin of the acid lime vesicles was confirmed by immunoblotting. After solubilization and partial purification of the two enzymes by gel filtration, their inhibitor profiles were largely unchanged. Based on equal ATPase activities, vesicles from sweet and acid limes were able to generate similar pH gradients. However, in tonoplast vesicles from sweet limes, the maximum $\Delta \mathrm{pH}$ was reached four times faster than in those from acid limes. Addition of ethylenediamine tetraacetic acid (EDTA) to chelate $\mathrm{Mg}^{+2}$ after the maximal $\Delta \mathrm{pH}$ was attained resulted in collapse of the pH gradient in vesicles from sweet limes, whereas no change in $\Delta \mathrm{pH}$ was observed in vesicles from acid limes, indicating a less $\mathrm{H}^{+}$ permeable membrane. Vacuolar ATPases from both cultivars exhibited identical pH optima and showed similar $\mathbf{M g}^{+2}$ dependence, but only the acid lime ATPase activity was inhibited by $\mathrm{Ca}^{+2}$. These data confirm that the vanadate-sensitive form of the V-ATPase found in lemon and acid limes is specific to hyperacidifying tissues rather than to citrus juice cells. Sweet lime vacuoles bear the classical V-ATPase also found in vegetative plant tissues.
\end{abstract}

The juice cells of most citrus fruit (Citrus L. sp.) accumulate high concentrations of citric acid and soluble sugars, and hyperacidify their vacuoles (Echeverria and Burns, 1989; Echeverria et al., 1992; Müller et al., 1996). In acid limes, for example, the vacuolar $\mathrm{pH}$ of juice cells has been determined to be as low as $\approx 2.0$ by two separate and independent methods (Echeverria and Burns, 1989; Echeverria et al., 1992). Juice cells of other citrus fruit such as lemons [Citrus limon (L.) Burm.] (Müller et al., 1996) and sweet oranges [Citrus sinensis (L.) Osbeck] (Echeverria and Burns, 1989) are also highly acidic, with $\mathrm{pH}$ values of 2.2 and 2.8 , respectively.

Vacuolar acidification in plant cells results from the $\mathrm{H}^{+}$pumping activity of two tonoplast-bound proton pumps, the V-ATPase and the V-PPase (Rea and Sanders, 1987). In most mature citrus fruit, the trans-tonoplast $\mathrm{pH}$ gradient exceeds the thermodynamic maximum $\Delta \mathrm{pH}$ attainable by the $\mathrm{V}$-PPase, suggesting that the $\mathrm{V}$ ATPase is the dominant pump (Davies, 1994; Schmidt and Briskin, 1993). In lemon juice cells, the large proton gradient between cytosol and vacuolar lumen $(\Delta \mathrm{pH})$ has been ascribed in

Received for publication 23 Feb. 2001. Accepted for publication 24 Oct. 2001 Florida Agricultural Experiment Station journal series R-07062.

${ }^{1}$ Postdoctorate associate.

${ }^{2}$ Research associate.

${ }^{3}$ Professor.

${ }^{4}$ Senior research assistant.

${ }^{5}$ Professor. part to the existence of a novel vanadate-sensitive, chloride and bafilomycin-insensitive tonoplast $\mathrm{H}^{+}$-ATPase, characteristics which are contrary to V-ATPase from plant tissues (Müller et al., 1996, 1997, 1999). When compared to tonoplast vesicles from epicotyls of the same species, those from the acidic juice cells were able to generate a larger $\Delta \mathrm{pH}$ in the presence of Mg.ATP. In addition, lemon fruit tonoplast vesicles maintained a preestablished $\mathrm{H}^{+}$gradient even after cessation of $\mathrm{H}^{+}$-ATPase by addition of EDTA, thus demonstrating a high degree of $\mathrm{H}^{+}$impermeability.

In a few citrus cultivars, the high citric acid content characteristic of most citrus fruit is absent. In such cultivars, the lower citrate content is associated with a higher vacuolar $\mathrm{pH}$. For example, the acidless sweet lime (Citrus limmetioides) accumulates only a fraction of the citric acid present in its close relatives Persian and Key limes (Citrus aurantifolia) and lemons, and is characterized by a vacuolar $\mathrm{pH}$ of $\approx 5.0$ (Echeverria and Burns, 1989). The vacuolar $\mathrm{H}^{+}$-ATPase is therefore subjected to a different regulatory environment in sweet limes than in acidic limes and lemons.

In the present report, we investigated whether the vanadate sensitive V-ATPase identified previously in lemon juice cells represents a form genetically adapted for vacuolar hyperacidification, or whether it is characteristic of citrus juice cells and differentially regulated in the less acidic cultivars. We found that only the acid lime V-ATPase shares characteristics previously observed in lemon juice sacs and appears to be specific to 
hyperacidifying citrus vacuoles, whereas, the sweet lime juice sac V-ATPase has features similar to those of lemon epicotyls and other vegetative V-ATPases.

\section{Materials and Methods}

Plant material. 'Palestine' sweet limes and 'Persian' acid limes were collected August to September 1997 from the Citrus Arboretum at the Florida Department of Agriculture, Winter Haven. For some experiments, acid limes were collected from the lime orchard at the Citrus Research and Education Center, Lake Alfred, Fla.

TONOPLAST ISOLATION. For isolation of tonoplast vesicles from both sweet and acid limes, the procedure of Müller et al. (1996) was followed with a few modifications. About $150 \mathrm{~mL}$ of juice cell extract were squeezed directly into $100 \mathrm{~mL}$ of homogenization buffer under continuous stirring. In order to keep the $\mathrm{pH}$ of the homogenate at around neutrality, the strength of the buffer varied depending on acidity of the fruit. For sweet limes, the homogenization buffer contained $0.5 \mathrm{~m} \mathrm{MOPS} / \mathrm{KOH}(\mathrm{pH} 8.5)$ and for acid limes the concentration was increased to $2 \mathrm{M}$. The homogenate was filtered through a $200 \mu \mathrm{m}$ pore size nylon mesh and centrifuged at $12,000 g_{\mathrm{n}}$ for $30 \mathrm{~min}$. After this first centrifugation step, the upper soft part of the pellet was resuspended and combined with the supernatant prior to ultracentrifugation for 30 min at $132,000 g_{\mathrm{n}}$. The resulting pellet was resuspended in resuspension buffer (Müller et al., 1996), layered onto an 8\%/ $17 \% / 26 \% / 34 \%$ sucrose gradient, and centrifuged for $60 \mathrm{~min}$ at $132,000 g_{\mathrm{n}}$. In contrast to the procedure of Müller et al. (1996), the sucrose gradient solutions used for these isolations did not contain bovine serum albumin (BSA), as it was found initially that BSA had no effect in recovery or stability of these membranes. Membrane vesicles at the interfaces were collected, rapidly diluted $10 \times$ with storage buffer of $10 \mathrm{~mm}$ Tris/Mes, $250 \mathrm{~mm}$ sorbitol, and $2 \mathrm{~mm}$ dithiothreitol (DTT) at pH 7.0, and centrifuged at $132,000 g_{\mathrm{n}}$ for $30 \mathrm{~min}$. After the final centrifugation, membrane samples were resuspended in $1 \mathrm{~mL}$ of storage buffer (at $\mathrm{pH} 7.0$ or $\mathrm{pH} 5.5$ depending on the experiments planned) and stored at -80 ${ }^{\circ} \mathrm{C}$ until needed. Before their use, all vesicles from sweet and acid lime were subjected to three freeze-thaw cycles to equilibrate the lumen with the same buffer solution and for experiments to be conducted under the same conditions.

Simultaneous measurement OF ATPaSe aCtivity AND PROTON PUMPING. Simultaneous measurements of ATPase activity and $\mathrm{H}^{+}$pumping capacity were performed as described by Palmgren (1990). ATP hydrolysis was coupled to the oxidation of NADH through pyruvate kinase/lactate dehydrogenase, and oxidation of $\mathrm{NADH}$ was measured at $340 \mathrm{~nm}$. Formation of a pH gradient was measured at $496 \mathrm{~nm}$ following the absorbance quenching of acridine orange. Reactions were started by addition of $\mathrm{MgCl}_{2}$ to a reaction mixture containing $50 \mu \mathrm{g}$ tonoplast vesicle protein. All reactions were carried out at $30{ }^{\circ} \mathrm{C}$ in a Shimadzu UV-160 spectrophotometer (Shimadzu Corp., Kyoto, Japan). Data points were recorded and plotted using the Grafit computer program (Erithacus Software Ltd., Horley Surrey, U.K.). All experiments were conducted at least three times.

IMMUNODETECTION OF V-PPASE. Sodium-dodecylsulfate gel electrophoresis (SDS-PAGE) was performed on slab gels containing $12.5 \%$ acrylamide and using the Laemmli buffer system (Laemmli et al., 1970). The gels were loaded with equal amount of membrane protein $(10 \mu \mathrm{g})$ for all samples. For western blot analysis, proteins were transferred electrophoretically from acrylamide gels to cellulose nitrate membranes and subsequently immunostainned. Polyclonal antibodies raised against purified mung bean [Vigna radiatae (L.) R. Wilcz.] V-PPase were kindly provided by M. Maeshima (Maeshima and Yoshida, 1989). Antibodies were detected with goat anti-rabbit IgG-conjugate alkaline phosphatase (AP) and visualized with bromochloroindollylphosphate-nitroblue tetrazolium (BCIP/NBT).

Purification of The V-ATPase. The V-ATPases from sweet and acid limes were solubilized and purified as described previously (Müller et al., 1997) with the following modifications. Fifteen milligrams of tonoplast-enriched sweet lime vesicles were solubilized with $2.5 \%$ octyl- $\beta$-glucoside in solubilization buffer (10 mм BTP-Mes, pH 7.6, 10\% glycerol, 1 mм EDTA, 8 mм $\mathrm{MgSO}_{4}, 5$ mм DTT, L- $\alpha$-phosphatidylcholine liposomes at $200 \mu \mathrm{g} \cdot \mathrm{mL}^{-1}$, and $0.012 \%$ butylated hydroxytoluene) in a total volume of $5 \mathrm{~mL}$. The solubilized proteins were centrifuged for 10 $\min$ at 412,000 gn in a rotor (TLA-100.3; Beckman Instruments, Inc., Paloalto, Calif). The supernatant was applied to a $100 \times 1$ $\mathrm{cm}$ Sephacryl S-400 HR (Amersham Pharmacia Biotech, Uppsala, Sweden) chromatography column equilibrated and eluted at 4.5 $\mathrm{mL} \cdot \mathrm{h}^{-1}$ in running buffer $(10 \mathrm{~mm}$ Tris-Mes, $\mathrm{pH} 7.0,0.3 \%(\mathrm{w} / \mathrm{w})$ Triton X-100, L- $\alpha$-phosphatidylcholine at $100 \mu \mathrm{g} \cdot \mathrm{mL}^{-1}, 10 \%$ glycerol, 1 mм EDTA, 4 mм $\mathrm{MgCl}_{2}, 5 \mathrm{~mm}$ DTT, and $50 \mu \mathrm{m}$ PMSF). Fractions with ATPase activity were pooled and applied to a Mono-Q anion exchange chromatography column (Pharmacia) equilibrated in $5 \mathrm{~mm}$ Tris- $\mathrm{HCl}, \mathrm{pH} 6.0,0.3 \%(\mathrm{w} / \mathrm{w})$ Triton X-100, L- $\alpha$-phosphatidylcholine at $50 \mu \mathrm{g} \cdot \mathrm{mL}^{-1}, 10 \%$ glycerol, $1 \mathrm{~mm}$ EDTA, 4 mM $\mathrm{MgCl}_{2}, 2$ mм DTT, and $50 \mu \mathrm{M}$ PMSF. The column was eluted with a linear 0 to $0.4 \mathrm{M} \mathrm{KCl}$ gradient, and the fractions with ATPase activity were pooled again, diluted to a final $\mathrm{KCl}$ concentration of $0.05 \mathrm{M}$, and applied to a second Mono-Q column. Elution from the second anion exchange column was performed with a $0.3 \mathrm{M} \mathrm{KCl}$ step gradient to recover all activity in one $0.5 \mathrm{~mL}$ fraction. The fraction containing ATPase activity was adjusted to

Table 1. ATPase activity in membrane fractions obtained from the interfaces of a discontinuous sucrose gradient. Original microsomal fractions were prepared from acid and sweet lime juice cells. Activity was determined in a coupled reaction with pyruvate kinase/lactate dehydrogenase and measured as the decrease in absorbance of NADH at $340 \mathrm{~mm}$.

\begin{tabular}{|c|c|c|c|c|c|c|}
\hline \multirow[b]{3}{*}{ Treatment } & \multicolumn{6}{|c|}{ Percent ATPase activity $\left(\mathrm{Pi}, \mathrm{nmol} \cdot \mathrm{min}^{-1} \cdot \mathrm{mg}^{-1}\right.$ protein $)$} \\
\hline & \multicolumn{2}{|c|}{$8 \% / 17 \%$} & \multicolumn{2}{|c|}{$17 \% / 26 \%$} & \multicolumn{2}{|c|}{$26 \% / 34 \%$} \\
\hline & Acid lime & Sweet lime & Acid lime & Sweet lime & Acid lime & Sweet lime \\
\hline Control (total activity) & $803(100 \%)$ & $656(100 \%)$ & $513(100 \%)$ & $531(100 \%)$ & $345(100 \%)$ & $328(100 \%)$ \\
\hline +Bafilomycin A (10 nM) & $96 \%$ & $6.6 \%$ & $96 \%$ & $10 \%$ & $94 \%$ & $50 \%$ \\
\hline$+\mathrm{NO}_{3}^{-}(50 \mathrm{mM})$ & $80 \%$ & $15 \%$ & $83 \%$ & $25 \%$ & $80 \%$ & $70 \%$ \\
\hline +Vanadate $(100 \mu \mathrm{M})$ & $31 \%$ & $68 \%$ & $34 \%$ & $60 \%$ & $75 \%$ & $80 \%$ \\
\hline+ Azide $(2 \mathrm{mM})$ & $94 \%$ & $80 \%$ & $75 \%$ & $72 \%$ & $40 \%$ & $38 \%$ \\
\hline
\end{tabular}




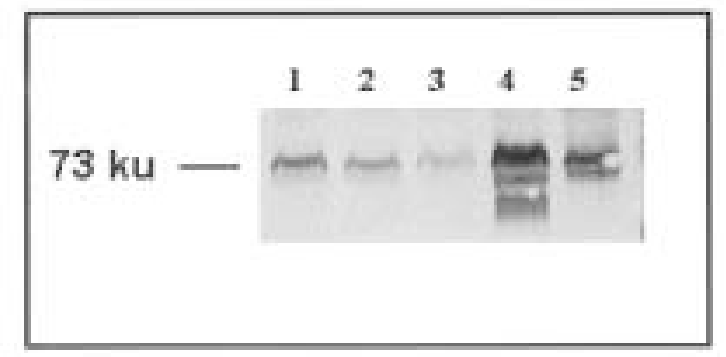

Fig. 1. Immunodetection of V-PPase in membrane samples from acid lime (lanes 1-3), sweet lime (lane 4), and red beet hypocotyl (lane 5) by antibodies against mung bean V-PPase. Lanes 1-3 correspond to the three interfaces of the sucrose gradient $(8 / 17,17 / 26$, and 26/34 interfaces, respectively). All lanes were loaded with $10 \mu \mathrm{g}$ total protein and $\mathrm{u}=$ unified atomic mass unit.

$2 \%$ octyl- $\beta$-glucoside, loaded onto a $12 \%$ to $25 \%$ glycerol gradient in $10 \mathrm{~mm}$ BTP-Mes, pH 7.0, 0.15\% Triton X-100, $1 \mathrm{~mm}$ EDTA, 4 mм $\mathrm{MgSO}_{4}, 10 \mathrm{~mm} \mathrm{KCl,} \mathrm{L-} \alpha$-phosphatidylcholine at 50 $\mu \mathrm{mol} \cdot \mathrm{L}^{-1}, 5 \mathrm{~mm} \mathrm{DTT}$, and $50 \mu \mathrm{M}$ PMSF, and centrifuged for $18 \mathrm{~h}$ at 250,000 $g_{\mathrm{n}}$ in a Beckman SW-41 rotor. The purified V-ATPase was used for activity measurements and its subunits analyzed by SDS-PAGE. The purification method for the acid lime $\mathrm{H}^{+}-$ ATPase was similar to that of sweet limes, except that the solubilization buffer contained only $1 \%$ octyl- $\beta$-glucoside, and after centrifugation of the solubilized membranes, the fluffy top layer of the pellet was resuspended and loaded together with the supernatant onto the Sephacryl S-400 HR column. In addition, before glycerol gradient centrifugation, the detergent concentration of the partially purified V-ATPase of acid limes was not adjusted to $2 \%$. Concentration of octyl- $\beta$-glucoside were optimized for solubilization and for the maintenance of V-ATPases integrity. These optimal concentrations were established after conducting solubility-activity curves for both types of V-APases under increasing concentrations of detergent.

Protein determination. Protein was determined as described by Bradford (1976) using Commassie Plus Protein Assay Reagent (Pierce Co. Rockford, Ill.).

\section{Results}

IDENTIFICATION OF TONOPLAST FRACTIONS. Isopycnic separation of microsomal samples from sweet and acid lime juice cells in a discontinuous sucrose gradient resulted in three distinct membrane layers. ATPase activity in the lightest fraction from sweet limes exhibited the typical inhibitor profile of tonoplast $\mathrm{H}^{+}$ATPases. The sweet lime enzyme was strongly inhibited by $\mathrm{NO}_{3}^{-}$ and bafilomycin $A_{1}$, and only slightly inhibited by vanadate or azide (Table 1). In contrast, the acid lime tonoplast ATPase activity was mostly insensitive to $\mathrm{NO}_{3}{ }^{-}$and bafilomycin $\mathrm{A}_{1}$, but was inhibited by high concentrations of vanadate.

To verify the vacuolar origin of the low density fractions from acid limes, we used antibodies raised against the mung bean VPPase (Maeshima and Yoshida, 1989). Highly pure tonoplast samples from red beet (Beta vulgrais L. ssp. vulgaris) hypocotyl (Echeverria and Gonzalez, 2000) and sweet lime (Echeverria et al., 1997) were included for comparative purposes (Fig. 1). Although some limited cross-reactivity was observed in all membrane fractions, the strongest antibody signal corresponding to $\mathrm{V}$ PPase was increasingly evident in samples from the lower density layers $(8 \% / 17 \%$ sucrose), confirming that tonoplast-enriched vesicles were recovered from these fractions (Fig. 1). In lemon juice cells, kinetic and biochemical characterization had already demonstrated the corresponding fractions to be of tonoplast origin (Müller et al., 1996, 1997, 1999). Secondary bands present in the sweet lime and red beet hypocotyl samples were attributed either to cross reactivity with aquaporin aggregates, or to proteolytic products of the V-PPase $73 \mathrm{ku}(\mathrm{u}=$ unified atomic mass unit) peptide (Maeshima, 1992). On a protein basis, the antibody cross-reactivity with acid lime tonoplast vesicles was significantly weaker than the signal obtained with sweet lime vesicles. This finding extends observations made in lemon, where, based on activity measurements, the V-PPase appeared to be only a minor constituent of the tonoplast membrane (Taiz, unpublished results). All subsequent experiments were performed with membranes collected from the lightest fractions.

The effects of increasing concentrations of bafilomycin $A_{1}$, $\mathrm{NO}_{3}{ }^{-}$, and vanadate on the tonoplast-bound ATPase from sweet and acid limes are presented in Fig. 2. Bafilomycin $\mathrm{A}_{1}$ had little

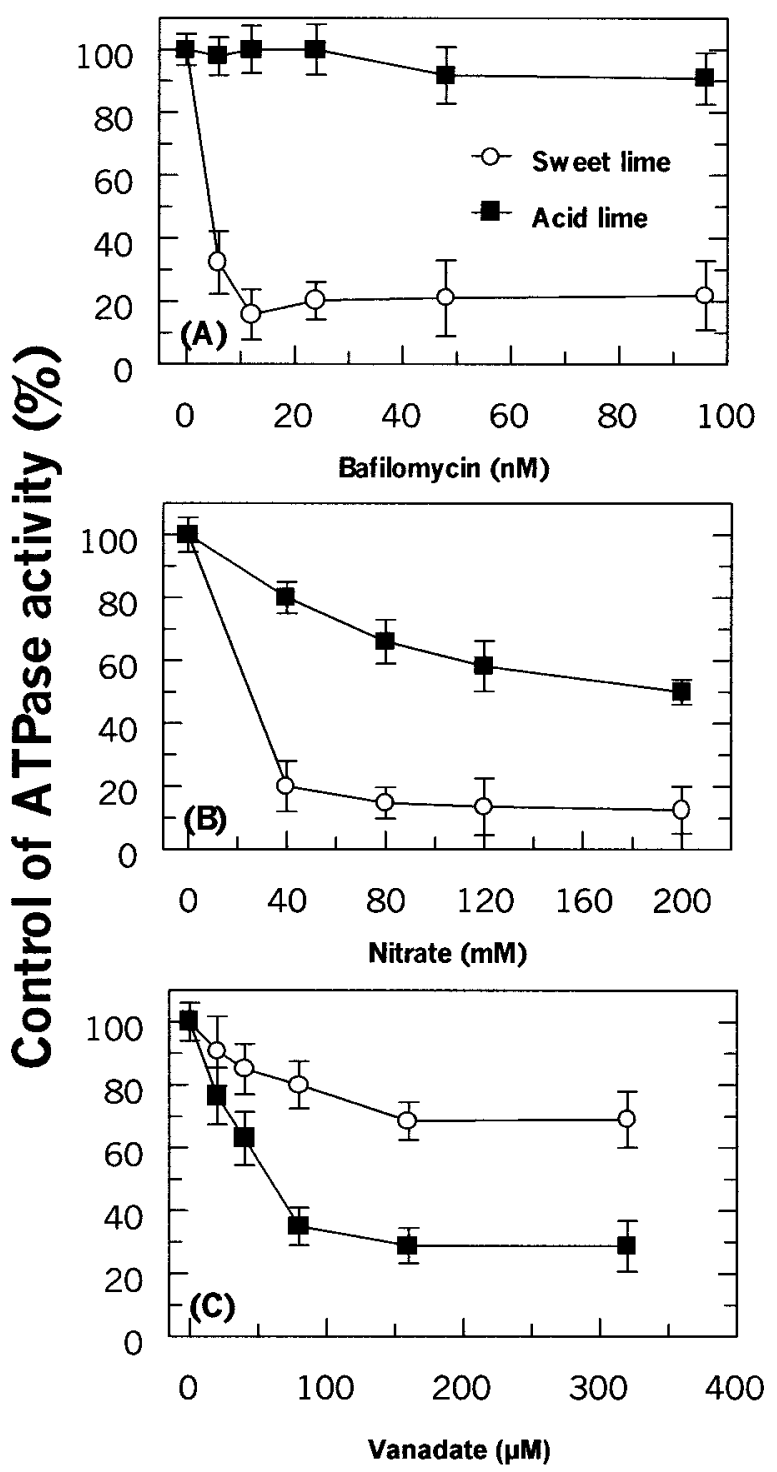

Fig. 2. Activity of acid and sweet lime juice cell V-ATPase in the presence of increasing concentrations of $(\mathbf{A})$ bafilomycin-A, $(\mathbf{B})$ nitrate, and $(\mathbf{C})$ vanadate. Activities were measured by following the oxidation of NADH in the presence of pyruvate kinase-lactic dehydrogenase at $340 \mathrm{~nm}$. Legend in A also applies to all figures and vertical bars $= \pm \operatorname{SD}(n=6)$. 
effect on acid lime ATPase even at concentrations of $100 \mathrm{~nm}$, whereas $10 \mathrm{~nm}$ inhibited corresponding activity from sweet limes by $90 \%$ (Fig. 2A). Acid lime tonoplast ATPase was partially inhibited by $\mathrm{NO}_{3}^{-}$, but the degree of inhibition was smaller than for the sweet lime ATPase (Fig. 2B) and the V-ATPases from other sources (Brauer et al., 1992; Hosaka et al., 1994; Williams et al., 1990).

Similar to what was found in lemon (Müller et al., 1996, 1997), acid lime V-ATPase activity was strongly inhibited by 20 to 100 $\mu \mathrm{M}$ vanadate (Fig. 2C). Only a small reduction in sweet lime VATPase activity was observed under the same conditions. The profiles of inhibition of the acid lime V-ATPase by vanadate, $\mathrm{NO}_{3}{ }^{-}$, and bafilomycin $\mathrm{A}_{1}$ are very similar to the profiles found in tonoplast-enriched vesicles of mature lemon juice cells, whereas the sweet lime juice cell V-ATPase resembles the V-ATPase of lemon epicotyls (Müller et al., 1996).

Kinetic Properties. V-ATPases from sweet and acid limes showed similar $\mathrm{pH}$ dependence with a $\mathrm{pH}$ optimum of 6.7 for both (data not presented). This value is slightly lower than the $\mathrm{pH} 7.0$
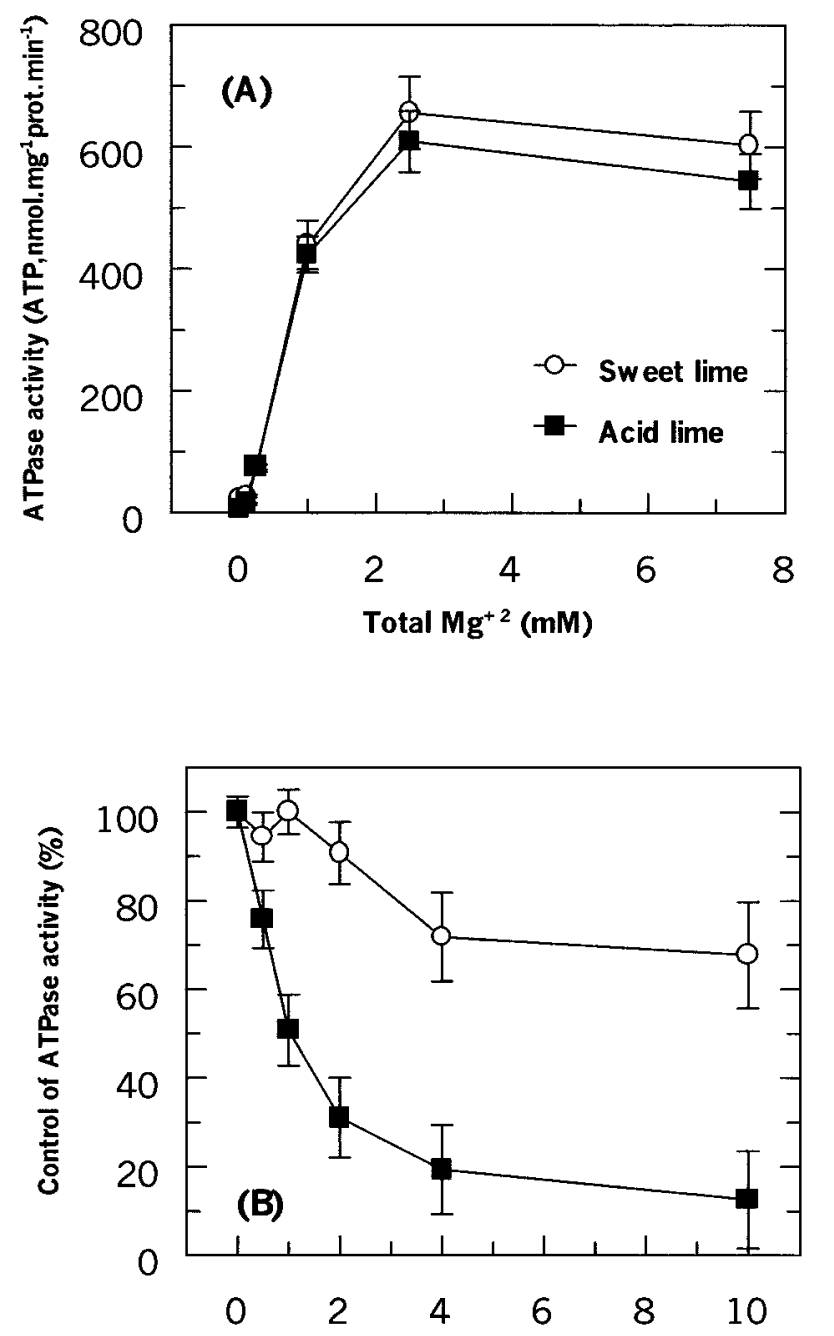

Total calcium (mM)

Fig. 3. Effect of (A) $\mathrm{Mg}^{+2}$ and (B) $\mathrm{Ca}^{+2}$ on the V-ATPase activity from acid and sweet lime juice cells. The reaction mixture contained $150 \mathrm{~mm} \mathrm{KCl}$ before addition of $\mathrm{MgCl}_{2}$. Activities were measured by following the oxidation of NADH in the presence of pyruvate kinase-lactic dehydrogenase at $340 \mathrm{~nm}$. Legend in A also applies to B and vertical bars $= \pm S \mathrm{SD}(n=6)$. optimum reported for lemon fruit and epicotyls (Müller et al., 1996), 7.5 for citrus leaves (Bañuls et al., 1993), and 8.0 in peanut (Arachis hypogaea L.) seedlings (Soma and Sharma, 1994). Sweet and acid limes were equally dependent on $\mathrm{Mg}^{+}$, and for both, the Michaelis-Menten curve was hyperbolic with an estimated $\mathrm{Km}$ of $\approx 1.0 \mathrm{~mm}$ (Fig. 3A). There was little effect of $\mathrm{Ca}^{2+}$ on sweet lime activity up to $10 \mathrm{~mm}$ (Fig. 3B). By contrast, under similar conditions, the acid lime V-ATPase activity was inhibited over $80 \%$ by $4 \mathrm{~mm} \mathrm{Ca}^{2+}$.

Formation OF $\mathrm{H}^{+}$GRADIENT AND MEMBRANE PERMEABILITY. The proton pumping activities of tonoplast enriched fractions from acid and sweet limes were compared by using acridine orange absorption quenching. Based on equivalent ATPase activity, both acid and sweet lime samples generated similar $\mathrm{pH}$ gradients (Fig. 4). However, sweet lime tonoplast membranes reached steady state faster than acid lime vesicles (6 min vs. 30 min in Fig. 4). After steady state was reached, addition of EDTA to chelate $\mathrm{Mg}^{2+}$ and stop the ATPase reaction resulted in collapse of the $\mathrm{pH}$ gradient within $10 \mathrm{~min}$ in tonoplast vesicles from sweet limes. In contrast, the $\mathrm{pH}$ gradient built up by acid lime vesicles was unaffected under similar conditions (Fig. 5). Addition of 10 $\mu \mathrm{M}$ gramicidin collapsed the remaining $\mathrm{pH}$ gradient in both cases. The impermeability of the acid lime tonoplast to protons was very comparable to that of the lemon tonoplast (Müller et al., 1996) and may be a common characteristic of highly acidic cells.

Purification of THE V-ATPases of SWeEt AND ACID LiMes. After solubilization with octyl- $\beta$-glucoside and centrifugation, the soluble ATPase activities from sweet and acid limes were layered onto a Sephacryl S-400 HR column for initial purification by gel filtration. Elution profiles are shown in Fig. 6. Consistent

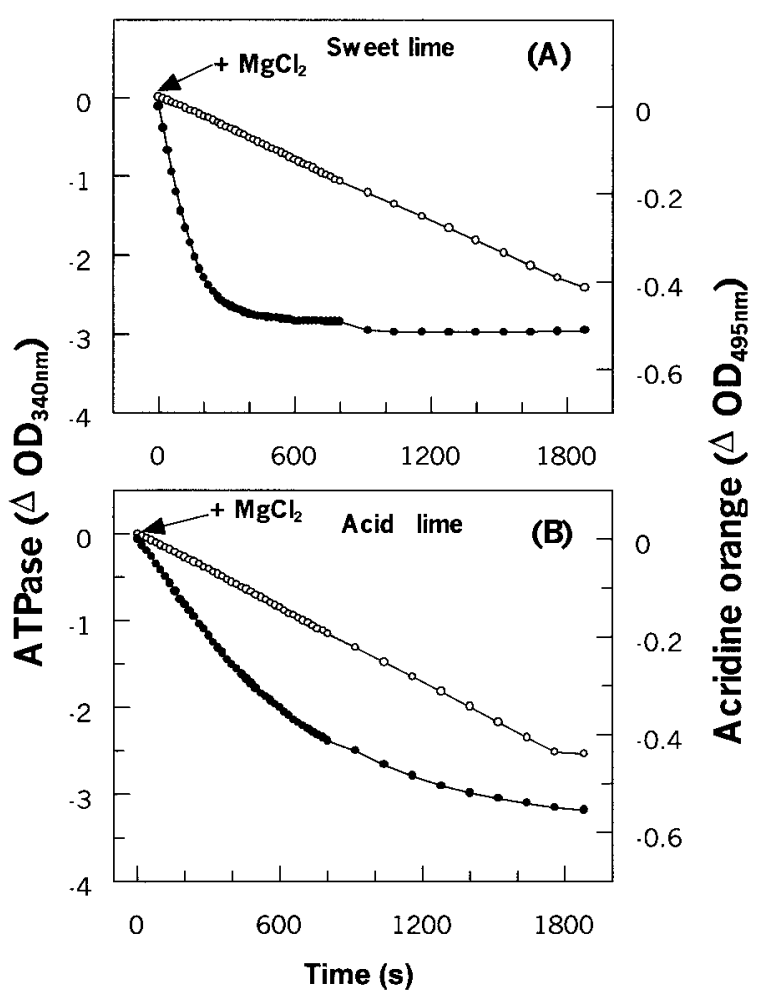

Fig. 4. Simultaneous measurements of $\mathrm{H}^{+} /$ATPase activity $\left(\mathrm{O}\right.$, left scale) and $\mathrm{H}^{+}$ gradient formation $(\boldsymbol{O}$, right scale) by $50 \mu \mathrm{g}$ tonoplast vesicles from (A) sweet lime and (B) acid lime juice cells. Reactions were started by addition of $\mathrm{MgCl}_{2}$ to a final concentration of $4 \mathrm{~mm}$. ATPase activity and $\mathrm{pH}$ formation were measured simultaneously as described in Materials and Methods. 


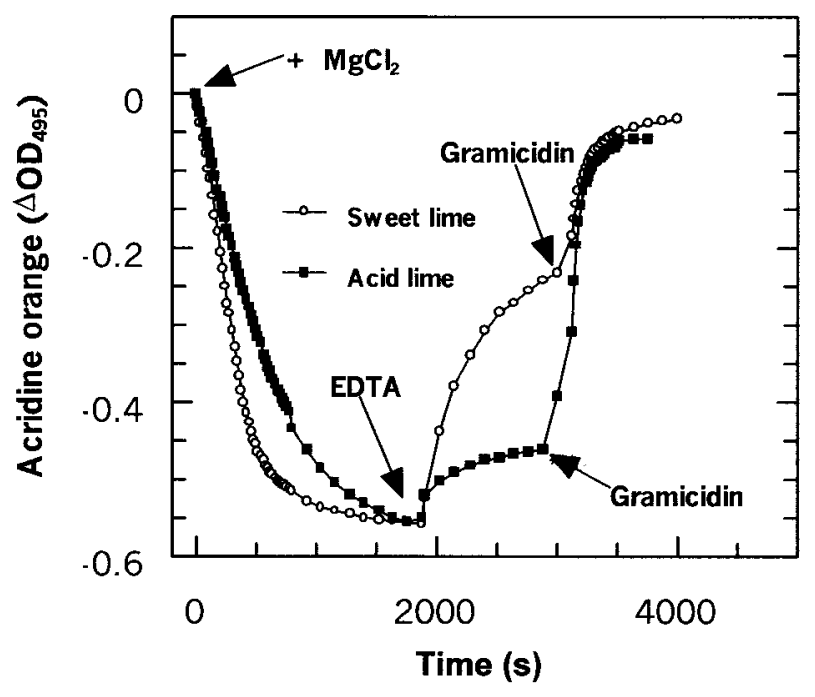

Fig. 5. Effect of $20 \mathrm{~mm}$ EDTA (to stop ATPase activity) and $10 \mu \mathrm{M}$ gramicidin on the established $\mathrm{H}^{+}$gradient in vesicles from sweet $(\mathrm{O})$ and acid (ם) lime juice cells.

with what was found previously for the V-ATPases from lemon juice sacs and epicotyls, the ATPase activities from sweet and acid limes eluted in a single peak. The partially purified sweet lime juice cell ATPase was found to be sensitive to nitrate but insensitive to inhibition by vanadate. In contrast, the partially purified acid lime ATPase was inhibited by both, nitrate and high concentrations of vanadate, and thus resembles the lemon fruit VATPase. The V-ATPases of sweet and acid limes were further purified by glycerol gradient centrifugation and anion exchange chromatography. The purified enzymes were then analyzed by SDS-PAGE. Results for the sweet lime V-ATPase are shown in Fig. 7. Subunits of $\approx 97,66,55,52,42 / 43,31,17$, and $13 \mathrm{ku}$ are visible. A $33 \mathrm{ku}$-band, like that found to comigrate with the ATPase activity of lemon fruit, was absent in the sweet lime V-ATPase and the pronounced $16 \mathrm{ku}$-band, previously described for lemon fruit, was barely visible in the sweet lime. Although a similar analysis of the acid lime V-ATPase indicated that it was enriched in the usual V-ATPase subunits, the acid lime enzyme was less stable than the sweet lime V-ATPase and appeared to disintegrate during the medium pressure Mono-Q anion exchange chromatography (data not presented).

\section{Discussion}

Acidification of the vacuolar compartment in plant cells is essential for maintenance of the electrochemical potential gradient $\left(\Delta \mu \mathrm{H}^{+}\right)$that serves to energize the secondary active transport of sugars (Getz, 1991; Keller, 1992), amino acids (Homeyer and Schultz, 1988), ions (Barkla and Pantoja, 1996; Schumaker and Sze, 1986), and a large number of secondary metabolites (Blom et al., 1991; Deus-Neumann and Zenk, 1986). The transport of organic anions into the vacuole is thought to be driven by the $\mathrm{H}^{+}$concentration difference across the tonoplast mem- brane (Brune et al., 1998; Oleski et al., 1987; Rentsch and Martinoia, 1991), generated by two electrogenic proton pumps, a V-ATPase and an inorganic V-PPase, with the V-ATPase being dominant in most tissues (Cheffings et al., 1997; Müller et al., 1996).

Most citrus fruit highly are acidic, a property associated with a high concentration of citric acid. In the exceedingly acidic Persian and Key limes (Citrus aurantifolia) and Bearss lemon, for example, the concentration of citric acid reaches beyond $325 \mathrm{~mm}$, whereas in the acidless sweet lime, citric acid does not exceed 5 $\mathrm{mm}$ (Echeverria and Ismail, 1987). Differential intracellular fractionation (Echeverria and Valich, 1988) and direct $\mathrm{pH}$ measurements (Echeverria et al., 1992) have established that the low $\mathrm{pH}$ of cell extracts and the intracellular location of citric acid can be ascribed to the large central vacuole.

Citrate accumulation in the vacuole of plant cells is determined primarily by the vacuolar $\Delta \mu \mathrm{H}^{+}$(Brune et al., 1998; Oleski et al., 1987; Rentsch and Martinoia, 1991). In citrus juice cells, although a portion of the accumulated citrate is transported by a $\Delta \mu \mathrm{H}^{+}$-independent, ATP-dependent uptake mechanism (Brune et al., 1998; Canel et al., 1995), the majority of the accumulation is driven by the $\Delta \mathrm{pH}$. Therefore, the final concentration of citric acid in the vacuole is dependent on the ability of the tonoplastbound ATPase to pump $\mathrm{H}^{+}$into the lumen, and on the permeability of the tonoplast to retain the $\mathrm{H}^{+}$. The V-PPase is unlikely to be

Fig. 6. Partial purification of the V-ATPases from (A) sweet and (B) acid limes. Membrane proteins from tonoplast-enriched vesicles from sweet limes and acid limes were solubilized with octyl- $\beta$-glucoside and separated on a $1 \times 100-\mathrm{cm}$ Sephacryl S-400 HR chromatography column. Profiles of the ATPase activity sensitive to $50 \mathrm{~mm}$ nitrate $(\bigcirc)$ or $100 \mu \mathrm{m}$ vanadate $(\mathcal{)})$ are shown. Legends in A applies to B.

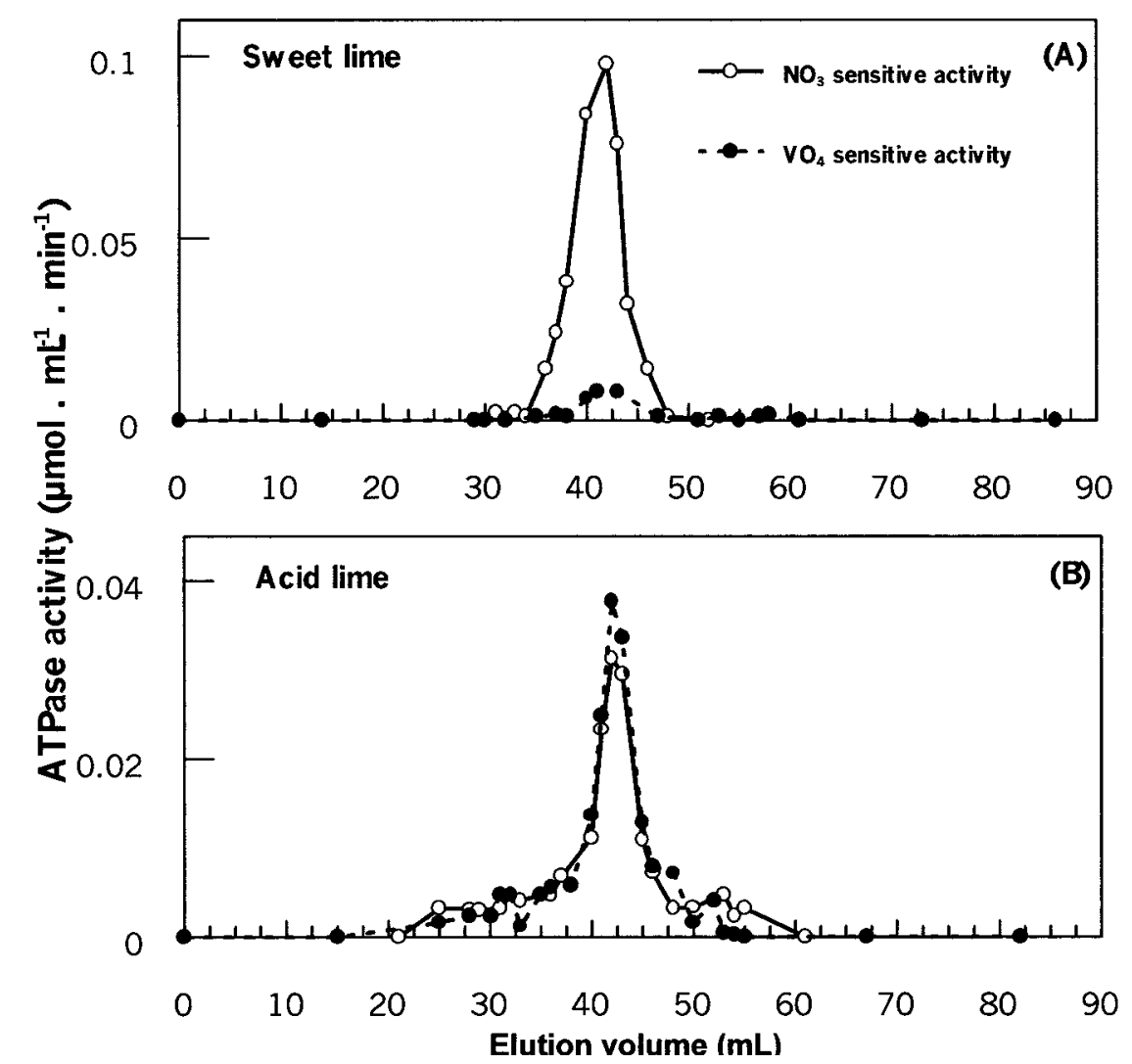


involved in hyperacidification for three reasons: 1) PPase activity in lemon fruit juice cells is negligible (Müller et al., 1996); 2) thermodynamic constraints prevent the V-PPase from generating such steep pH gradients (Schmidt and Briskin, 1993); and 3) VPPase activity in acidic citrus fruit has been demonstrated to function in the PPi synthesis direction rather than in the hydrolytic mode (Marsh et al., 2000)

Müller et al. (1996) suggested that vacuolar hyperacidification in lemon juice cells was facilitated by a novel tonoplast-bound VATPase that was sensitive to high concentrations of vanadate. This enzyme was absent from lemon epicotyl cells which exhibited a higher vacuolar $\mathrm{pH}$. In addition, the tonoplast of juice cells was more impermeable to protons than that of epicotyls. The results of the present investigation confirm that hyperacidification in juice cells of acidic citrus fruit is achieved via a vanadatesensitive V-ATPase and a tonoplast that is impermeable to $\mathrm{H}^{+}$ diffusion. This conclusion is based on: 1) data demonstrating that a vanadate and $\mathrm{Ca}^{2+}$ sensitive, $\mathrm{NO}_{3}$ and bafilomycin insensitive V-ATPase (Figs. 2 and 3) similar to that of lemon, is present at the tonoplast of acid limes juice cells, but absent from the tonoplast of a high $\mathrm{pH}$, low citrate variety; 2) an apparent lower $\mathrm{H}^{+}$/ATP coupling ratio for the acid lime V-ATPase (Fig. 4), which may be necessary to reach the trans tonoplast $\mathrm{pH}$ difference observed in vivo; and 3) notable differences in the ability of the tonoplasts to maintain a $\mathrm{pH}$ gradient after inactivation of the V-ATPase (Fig. 5).

Compared to the V-ATPases from sweet limes and those from sugarcane (Saccharum officinarum L.) (Williams et al., 1990), pear (Pyrus communis L.) fruit (Hosaka et al., 1994) and maize (Zea mays L.) roots (Brauer et al., 1992), tonoplast-bound ATPases from lemon and acid lime juice cells are unusual in their lack of sensitivity to bafilomycin $\mathrm{A}_{1}, \mathrm{NO}_{3}^{-}$, and by their sensitivity to vanadate. This unusual inhibitor profile was maintained during purification of the enzyme by gel filtration and anion exchange chromatography, and thus appears to represent a hallmark of hyperacidifying proton pumps in Citrus. The conventional inhibitor profile of the sweet lime V-ATPase proves that juice cells with less acidic vacuoles do not possess the vanadatesensitive pump.

When normalized to the initial rates

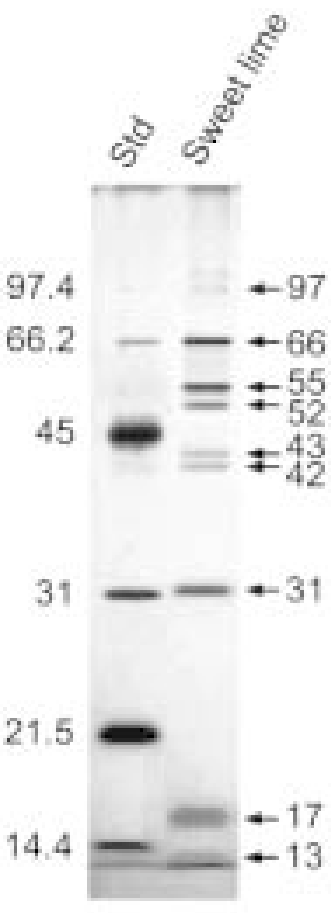
of $\mathrm{H}^{+}$pumping, Müller et al. (1996) noted that the lemon juice cell VATPase was able to generate a significantly larger $\Delta \mathrm{pH}$ than the corresponding enzyme from epicotyls. However, when based on identical ATPase activity rates, the lemon fruit and epicotyl enzymes reached similar $\mathrm{pH}$ gradients, with the fruit enzyme taking twice as long to reach equilibrium as the epicotyl V-ATPase (Müller et al., 1999). This was also the case for acid and sweet lime juice cell samples when compared on an equal V-AT-

Fig. 7. SDS-polyacrylamide gel of the purified V-ATPase from sweet lime. The solubilized VATPase from sweet lime was purified by gel filtration, anion exchange chromatography, and glycerol gradient centrifugation, and separated by gel electrophoresis. The molecular weight of standard proteins (Std) is indicated on the left of the gel. V-ATPase subunits are identified on the right.
Pase activity basis (Fig. 4). Although both V-ATPases were able to generate comparable $\Delta \mathrm{pHs}$, the $\mathrm{H}^{+}$pumping rate of the sweet lime ATPase was virtually double that of acid limes, suggesting a difference in their $\mathrm{H}^{+} / \mathrm{ATP}$ coupling ratio.

In agreement with the previous characterization of lemon fruit $\mathrm{V}$ ATPase (Müller et al., 1996, 1997, 1999), formation and maintenance of the large $\Delta \mathrm{pH}$ across the tonoplast of highly acidic citrus juice cells is made possible by the presence of a specialized VATPase and a tonoplast highly impermeable to $\mathrm{H}^{+}$. The low vacuolar $\mathrm{pH}$ of $\approx 2.0$, and a trans-tonoplast $\Delta \mathrm{pH}$ of about five units are sufficient to drive the uptake of $325 \mathrm{~mm}$ citric acid from a cytosolic citrate concentration of $<10 \mathrm{~nm}$ (Brune et al., 1998). This capacity for vacuolar hyperacidification is absent from citrus fruit and other vegetative cells with a higher vacuolar $\mathrm{pH}$. Therefore, the novel vanadate-sensitive V-ATPase described for lemons and acid limes appears to be a characteristic of hyperacidifying tissues and not a property of citrus juice cells in general.

\section{Literature Cited}

Bañuls, J., R. Ratajczak, and U. Luttge. 1993. Characterization of a proton-translocating ATPase in a tonoplast-vesicle fraction from citrus. J. Plant Physiol. 142:319-324.

Barkla, B. and O. Pantoja. 1996. Physiology of ion transport across the tonoplast of higher plants. Annu. Rev. Plant Physiol. Plant Mol. Biol. 47:159-184.

Blom, T.J.M., M. Sierra, T.B. van Vliet, M.E.I. Franke, P. de Koning, F. van Iren, R. Verpoorte, and K.R. Libbenga. 1991. Uptake and accumulation of ajmalicine into isolated vacuoles of cultured cells of Catharanthus roseus and its conversion to serpentine. Planta 183:170 177.

Bradford, M.M. 1976. A rapid and sensitive method for the quantitation of microgram quantities of protein utilizing the principle of protein-dye binding. Anal. Biochem. 72:248-254.

Brauer, D., C. DeNea, and S.I. Tu. 1992. Effects of $\mathrm{pH}$ on proton transport by vacuolar pumps from maize roots. Physiol. Plant. 86:6370.

Brune, A., P.C. Gonzalez, U. Goren, R. Zehavi, and E. Echeverria. 1998. Citrate uptake into tonopast vesicles from acid lime (Citrus aurantifolia) juice cells. J. Membrane Biol. 166:197-203.

Canel, C., J.N. Bailey-Seres, and M. Roose. 1995. In vitro $\left[{ }^{14} \mathrm{C}\right]$ citrate uptake by tonoplast vesicles of acidless citrus juice cells. J. Amer. Soc. Hort. Sci. 120:510-514.

Cheffings, C.M., O. Pantoja, F.M. Ashcroft, and J.A.C. Smith. 1997. Malate transport and vacuolar ion channels in CAM plants. J. Expt. Bot. 48:623-631.

Davies, J.M. 1994. The bioenergetics of vacuolar $\mathrm{H}^{+}$pumps. Adv. Bot. Res. 25:339-362.

Deus-Neumann, B. and M.H. Zenk. 1986. Accumulation of alkaloids in plant vacuoles does not involve an ion-trap mechanism. Planta 167:44 53.

Echeverria, E. and J.K. Burns. 1989. Vacuolar acid hydrolysis as a physiological mechanism for sucrose breakdown. Plant Physiol. 90:530 533.

Echeverria, E., J.K. Burns, and H. Felle. 1992. Compartmentation and cellular conditions controlling sucrose breakdown in mature acid lime fruit. Phytochemistry 31:4091-4095.

Echeverria E. and P.C. Gonzalez. 2000. ATP-induced sucrose efflux from red beet tonoplast vesicles. Planta 211:77-84.

Echeveria, E., P.C. Gonzalez, and A. Brune. 1997. Characterization of proton and sugar transport at the tonoplast of sweet lime (Citrus limmetioides) juice cells. Physiol. Plant. 101:291-300.

Echeverria, E. and M. Ismail. 1987. Changes in sugars and acids of citrus fruits during storage. Proc. Fla. State. Hort. Soc. 100:50-52.

Echeverria, E. and J. Valich. 1988. Carbohydrate and enzyme distribution in protoplasts from 'Valencia' orange juice sacs. Phytochemistry 27:73-76. 
Getz, H.P. 1991. Sucrose transport in tonoplast vesicles of red beet roots is linked to ATP hydrolysis. Planta 185:261-268.

Homeyer, U. and G. Schultz. 1988. Transport of phenylalanine into vacuoles isolated from barley mesophyll protoplasts. Planta 176:378 382.

Hosaka, M., Y. Kanayama, K. Shiratake, and S. Yamaki. 1994. Tonoplast $\mathrm{H}^{+}$-ATPase of mature pear fruit. Phytochemistry 36:565-567.

Keller, F. 1992. Transport of stachyose and sucrose by vacuoles of Japanese artichoke (Stachys sieboldii) tubers. Plant Physiol. 98:442445.

Laemmli, U.K. 1970. Cleavage of structural proteins during the assembly of the head of bacteriophage T4. Nature 227:680-685.

Maeshima, M. 1992. Characterization of the major integral protein of vacuolar membrane. Plant Physiol. 98:1248-1254.

Maeshima, M. and S. Yoshida. 1989. Purification and properties of vacuolar membrane proton-translocating inorganic pyrophosphatase from mung bean. J. Biol. Chem. 264:20068-20073.

Marsh, K., P. Gonzalez, and E. Echeverria. 2000. PPi formation by reversal of the tonoplast-bound $\mathrm{H}^{+}$-pyrophosphatase from 'Valencia' orange juice cells. J. Amer. Soc. Hort. Sci. 125:420-424.

Müller, M.L., U. Irkens-Kiesecker, D. Kramer, and L. Taiz. 1997. Purification and reconstruction of the vacuolar $\mathrm{H}^{+}$-ATPases from lemon fruits and epicotyls. J. Biol. Chem. 272:12762-12770.

Müller, M.L., U. Irkens-Kiesecker, B. Rubinstein, and L. Taiz. 1996. On the mechanism of hyperacidification in lemon. Comparison of the vacuolar $\mathrm{H}^{+}$-ATPase of fruits and epicotyls. J. Biol. Chem. 271:1916-
1924.

Müller, M.L., M. Jensen, and L. Taiz. 1999. The vacuolar H+-ATPase of lemon fruits is regulated by variable $\mathrm{H}^{+} / \mathrm{ATP}$ coupling and slip. J. Biol. Chem. 274:10706-10716.

Oleski, N., P. Mahdavi, and A. Bennett. 1987. Transport properties of the tomato fruit tonoplast. II. Citrate transport. Plant Physiol. 84:9971000 .

Palmgren, M.G. 1990. An $\mathrm{H}^{+}$-ATPase assay: Proton pumping and ATPase activity determined simultaneously in the same sample. Plant Physiol. 94:882-886.

Rea, P.A. and D. Sanders. 1987. Tonoplast energization: Two pumps, one membrane. Physiol. Plant. 71:131-141.

Rentsch, D. and E. Martinoia. 1991. Citrate transport into barley mesophyll vacuoles: Comparison with malate-uptake activity. Planta 184:532-537.

Schmidt, A.L. and D. Briskin. 1993. Energy transduction in tonoplast vesicles from red beet (Beta vulgaris) storage tissue: $\mathrm{H}^{+} /$substrate stoichiometries for the $\mathrm{H}^{+}$-ATPase and $\mathrm{H}^{+}$-PPase. Arch. Biochem. Biophys. 301:165-173.

Schumaker, K.S. and H. Sze. 1986. Calcium transport into the vacuole of oat roots. J. Biol. Chem. 261:12172-12178.

Soma, S. and V. Sharma. 1994. Tonoplast ATPase from peanut seedlings. Phytochemistry 36:569-572.

Williams, L., M. Thom, and A. Maretzki. 1990. Characterization of a proton translocating ATPase and sucrose uptake in a tonoplast-enriched vesicle fraction from sugarcane. Physiol. Plant. 80:169-176. 